\title{
Thermally assisted self-healing and shape memory behaviour of natural rubber based composites
}

\author{
Q. Wang, J. Meng, Y. Ma, L. Xia*
}

Key Laboratory of Rubber-Plastics, Ministry of Education/Shandong Provincial Key Laboratory of Rubber-Plastics, School of Polymer Science and Engineering, Qingdao University of Science and Technology, 266042 Qingdao, P. R. China

Received 30 March 2021; accepted in revised form 22 May 2021

\begin{abstract}
A series of novel shape memory and self-healing composites of natural rubber (NR) and polycyclooctene (PCO) were designed using a simple physical blending method. These two polymers were selected with the intent of introducing network flexibility and mobility into the prepared blends. The mechanical, curing, thermal, shape memory, and thermally assisted self-healing properties of the NR/PCO composites were investigated in this study. In these composites, the crosslinked network generated in both the NR and PCO portions acted as a fixed phase, while the crystalline regions of the PCO portions acted as a reversible phase in the shape memory behavior. The composites showed self-healing properties at an elevated temperature $\left(90^{\circ} \mathrm{C}\right)$, which was attributed to molecular chain interdiffusion processes. Shape memory and thermally assisted self-healing properties were improved by increasing polycyclooctene content. The NR/PCO showed superior mechanical, shape memory, and self-healing properties $\left(R_{\mathrm{f}}=94.57 \%, R_{\mathrm{r}}=98.92 \%\right.$ and healing efficiency $\left.=19.03 \%\right)$ when the blending ratio was $50 / 80$. Due to these superior properties, this kind of natural rubber-based composites may have the potential to be used in intelligent and thermal-response shape memory fields.
\end{abstract}

Keywords: natural rubber, polycyclooctene, shape memory, self-healing

\section{Introduction}

Stimuli-responsive materials with controllable shapechanging behaviors are highly desirable in various device applications. Shape memory polymers (SMPs) possess the capacity to maintain temporary shapes and recover to their permanent shape when subjected to an appropriate external stimulus $[1,2]$, such as temperature [3-5], $\mathrm{pH}[6,7]$, light $[8,9]$, water $[10,11]$, and magnetic or electric fields [12-15]. SMPs are thought to have great development prospects due to their many potential applications in many areas, including smart textiles, adhesives, high-performance sensors, aerospace applications, and biomedical devices [16-20].

The combination of fixed domains and reversible domains is an interesting and challenging process to create shape-memory materials. Generally, crosslinked bonds can be used as a stable network that contributes to forming the material's original permanent shape and improving the shape recovery rate [21]. Crystalline phases or glass transition processes can be used to fix temporary shapes subjected to external stimuli, such as heating, $\mathrm{pH}$, and water [22]. Classical SMPs typically exhibit a one-way shape memory effect, in which programming is necessary for each shape memory cycle, and there is only one temporary shape. There are also SMPs with a twoway shape memory effect, which complete a reversible shape conversion between two predefined shapes without repeated programming. In addition, a multi-shape memory effect yields two or more temporary shapes when subjected to different external 
stimuli. These multidimensional shape memory behaviors expand the applications of SMPs in future device applications [23-25].

Self-healing polymers (SHPs), another class of smart materials, have also received considerable attention due to their ability to spontaneously repair themselves after suffering surface or internal damage $[26,27]$. Throughout the service life of materials, they experience local microscopic and even macroscopic damage that is irreversible in most cases, particularly in conventional vulcanized natural or synthetic rubbers, due to their chemical crosslinked three-dimensional molecular network. Recently, research on self-healing elastomer materials has made great progress, including the development of supramolecular rubber, ionic and covalent interaction self-healing rubber; and shape memory effects to assist self-healing [28-29]. Self-healing SMPs based on various structures have been developed, including polyurethanes (PU), polystyrene copolymers, and epoxy-based polymers [3032]. Shape memory-assisted self-healing (SMASH) was firstly introduced by Luo and Mather [33]. Li and coworkers [34-36] proposed a two-step healing scheme called 'close then heal' $(\mathrm{CTH})$, in which the confined shape recovery of SMP was used to seal or close cracks to improve the self-healing of materials. Raidt developed ionically crosslinked shape-memory polypropylene recently, which had SMASH [37]. However, SHPs still have some critical defects, such as complex preparation processes, reduced mechanical performance, and low self-healing efficiency, which hinder their practical applications. Therefore, it is imperative to find a simple and low-cost manufacturing method to develop elastomers with sufficient mechanical strength and excellent self-healing capability.

Concerning the sustainable development of materials, there is an urgent desire to develop new materials with an effective combination of the shape memory effect and self-healing ability. This manuscript reports a novel type of SMP, which is simply fabricated by a physical blending method, containing natural rubber (NR) and polycyclooctene (PCO). Natural rubber is widely used in industry, transportation; national defense; medicine and health; machinery manufacturing, and daily life due to its strong elasticity, good insulation, and plasticity. Katzenberg and coworkers $[38,39]$ found that natural rubber itself had excellent shape memory properties. In addition, their team also discovered through research that stretched, programmed NR was a material that had an internal memory, and the trigger point of NR could be manipulated mechanically [40-42]. There are also some related studies on the self-healing of modified natural rubber $[43,44]$. As a semicrystalline polyolefin material, PCO exhibits certain structural advantages as an SMP with a high content of double bonds and crystalline resignment [45-48]. Segiet et al. [49] studied the polymer IR, which is similar in structure to natural rubber, and explored the effects of stearic acid and biocompatible poly(2-ethyl-2-oxazoline) (PEtOx) on its shape memory, respectively. They found IR/PEtOx was also a water-triggerable SMP that could be applied for biomedical purposes. In this study, thermally actuated shape memory polymers (SMPs) of chemically crosslinked NR/PCO were prepared via mechanical blending. The chemically crosslinked blends behaved as an elastomer, which could be arbitrarily shaped above the melting temperature of the crystalline phase and subsequently become fixed during crystallization. The mechanical, thermal, shape memory and thermally assisted selfhealing properties of NR/PCO composites were investigated in detail in this manuscript. Two schematic diagrams were proposed to show the shape memory and self-healing behaviors of NR/PCO composites. NR/PCO composites displayed excellent shape memory and thermally assisted self-healing properties with increasing PCO content. Due to these superior properties, this series of natural rubber-based composites may have the potential to be used in intelligent and thermal-response shape memory fields.

\section{Experimental}

\subsection{Materials}

NR (STR 10, Sri Trang Agro-Industry Plc, Thailand), PCO (Vestenamer ${ }^{\circledR} 8012$, weight-average molecular weight $90000 \mathrm{Da}$, trans content $80 \%$, Evonik Industries, Shanghai, China), dicumyl-peroxide (DCP, purity 96\%, Aladdin Co., Ltd. Shanghai, China), and other additives were obtained from commercial sources and used without further purification.

\subsection{Preparation of the NR/PCO composites}

NR/PCO composites were prepared with a high-temperature open mill at $50^{\circ} \mathrm{C}$ for approximately $10 \mathrm{~min}$ using a standard mixing sequence. The compound formulations are shown in Table 1. 
Table 1. Formulation of NR/PCO composites.

\begin{tabular}{|c|c|c|c|c|}
\hline Formulation & $\mathbf{A}$ & B & $\mathrm{C}$ & D \\
\hline NR & 50 & 50 & 50 & 50 \\
\hline $\mathrm{PCO}$ & 50 & 60 & 70 & 80 \\
\hline $\mathrm{DCP}$ & 1.5 & 1.5 & 1.5 & 1.5 \\
\hline Antioxidant MB [g] & 2 & 2 & 2 & 2 \\
\hline $\mathrm{ZnO}$ & 5 & 5 & 5 & 5 \\
\hline SA & 1 & 1 & 1 & 1 \\
\hline
\end{tabular}

\subsection{Curing characteristics}

The curing characteristics of the blends were studied with a Monsanto oscillating disc rheometer at $160^{\circ} \mathrm{C}$ according to ASTM D-2084-11.

\subsection{Nuclear magnetic resonance (NMR) and equilibrium swelling crosslinking density test}

Crosslink density was tested using an XLDS-15 HT Cross-link Density Analyser (IIC DR. KUHN GmbH \& Co KG, Germany) under a magnetic induction intensity of $3.5 \mathrm{~A} / \mathrm{m}$, a frequency of $15 \mathrm{MHz}$, and a test temperature of 60 to $80^{\circ} \mathrm{C}$. Parker et al. [50] established the relationship between the NMR relaxation parameters and the structure of vulcanized rubber. In this study, the transverse relaxation time $\left(T_{2}\right)$ is used to characterize the change in crosslink density. For ease of understanding, $T_{2}$ decreases as the crosslink density increases. The crosslink density of the vulcanized NR/PCO blends was also determined by the method of equilibrium swelling. The vulcanized test pieces were swollen in toluene at room temperature for 48 hours. After removing the excess solvent, the weights of the swollen samples $\left(W_{1}\right)$ were recorded. Finally, the samples were dried in a vacuum oven at $50{ }^{\circ} \mathrm{C}$ for 12 hours, and the weights of the dried samples $\left(W_{2}\right)$ were recorded. The crosslink density $\left(V_{\mathrm{e}}\right)$ was determined according to the Flory-Rehner equation (Equation (1)):

$V_{\mathrm{e}}=\frac{\ln \left(1-V_{\mathrm{r}}\right)+V_{\mathrm{r}}+\chi V_{\mathrm{r}}^{2}}{V_{l}\left(V_{\mathrm{r}}^{1 / 3}-\frac{V_{\mathrm{r}}}{2}\right)}$

where $V_{1}$ is the molar volume of the solvent; $\chi$ is the interaction parameter between the solvent and the polymer; and $V_{\mathrm{r}}$ is the volume fraction of the polymer in the swollen samples, which can be calculated by Equation (2):

$$
V_{\mathrm{e}}=\frac{\frac{W_{2}}{\rho_{2}}}{\frac{W_{2}}{\rho_{2}}+\frac{W_{1}-W_{2}}{\rho_{1}}}
$$

where $\rho_{1}$ and $\rho_{2}$ are the densities of the solvent and polymer, respectively.

\subsection{Scanning electron microscope}

The microscopic morphology of the NR/PCO composites was observed by a field-emission scanning electron microscope (SEM) (JEOL JSM-6700F, Japan).

\subsection{Mechanical characterization}

Vulcanized slabs were prepared by compression molding, and dumbbell-shaped specimens were diecut according to the following dimensions: length $=$ $20 \mathrm{~mm}$, thickness $=2 \mathrm{~mm}$, the width of the parallel part $=4 \mathrm{~mm}$, as noted in ASTMD 412-type C (Wuxi KLT Precision Hydraulic Machinery Factory, Wuxi, China). The tests were conducted following the ASTM D $412-16$ procedures. The $100 \%$ modulus, elongation at break, and tensile strength were measured at room temperature using a tensile testing machine (Lloyd, LR10 K Plus, UK) at a jaw separation speed of $500 \mathrm{~mm} \cdot \mathrm{min}^{-1}$.

\subsection{Differential scanning calorimetry (DSC)}

DSC measurements were performed using a DSCQ20 (TA Instruments, USA) in a $\mathrm{N}_{2}$ atmosphere. The temperature and enthalpy were calibrated with an indium standard. Samples with a mass of $6 \sim 10 \mathrm{mg}$ were maintained at $100^{\circ} \mathrm{C}$ for $3 \mathrm{~min}$ to eliminate their thermal histories before they were cooled to $-50^{\circ} \mathrm{C}$ at a speed of $10^{\circ} \mathrm{C} \cdot \mathrm{min}^{-1}$. Samples were subsequently heated to $100^{\circ} \mathrm{C}$ at a rate of $10^{\circ} \mathrm{C} \cdot \mathrm{min}^{-1}$. The first cooling and subsequent second heating traces were recorded for analysis. The degree of crystallinity $\left(X_{\mathrm{c}}\right)$ for each portion of the composites was calculated by Equation (3):

$X_{\mathrm{c}}=\frac{\Delta H_{\mathrm{m}}}{\omega \cdot \Delta H_{\mathrm{m}}^{*}} \cdot 100 \%$

where $\Delta H_{\mathrm{m}}$ and $\Delta H_{\mathrm{m}}^{*}$ are the melting enthalpy of the polymer and its theoretical melting enthalpy (ca. $230 \mathrm{~J} \cdot \mathrm{g}^{-1}$ for PCO), respectively [51], $\omega$ is the mass fraction of $\mathrm{PCO}$ component in NR/PCO composites.

\subsection{Shape memory effect}

The shape memory properties of the composites were analyzed by a DMA-Q800 instrument (TA Instruments, New Castle, Delaware, USA) in 'Controlled Force' mode with a preload of $0.001 \mathrm{~N}$ and a 
frequency of $1 \mathrm{~Hz}$. The test samples were cut into rectangular shapes with a thickness of $2.0 \mathrm{~mm}$, a width of $4.0 \mathrm{~mm}$, and a length of $30.0 \mathrm{~mm}$. The initial clamp gap was set to 5.0 to $10.0 \mathrm{~mm}$. The heating and cooling rates were both set to $5^{\circ} \mathrm{C} \cdot \mathrm{min}^{-1}$. The procedures of the shape memory effect were as follows.

First, the sample was maintained isothermally at $100^{\circ} \mathrm{C}$ for 3 minutes to completely melt the crystalline regions of the PCO part; the initial strain was denoted as $\varepsilon_{0}$. Second, stress of $3 \mathrm{~N}$ was applied at a speed of $0.3 \mathrm{~N} \cdot \mathrm{min}^{-1}$, and the sample was cooled to $-50^{\circ} \mathrm{C}$ at a speed of $5{ }^{\circ} \mathrm{C} \cdot \mathrm{min}^{-1}$ to freeze the crystalline domain completely $\left(\varepsilon_{1, \text { load }}\right)$. Then, the load was removed at a speed of $0.3 \mathrm{~N} \cdot \mathrm{min}^{-1}\left(\varepsilon_{1}\right)$. Finally, the sample was reheated to $100{ }^{\circ} \mathrm{C}$ at a speed of $5{ }^{\circ} \mathrm{C} \cdot \mathrm{min}^{-1}$ and maintained isothermally for $10 \mathrm{~min}$ $\left(\varepsilon_{0, \text { rec }}\right)$. The shape fixity ratio $\left(R_{\mathrm{f}}\right)$ (Equation (4)) and shape recovery ratio $\left(R_{\mathrm{r}}\right)$ (Equation (5)) are critical parameters for SME characterization and can be quantified as follows:

$$
\begin{aligned}
& R_{\mathrm{f}}(0 \rightarrow 1)=\frac{\varepsilon_{1}-\varepsilon_{0}}{\varepsilon_{1, \text { load }}-\varepsilon_{0}} \cdot 100 \% \\
& R_{\mathrm{r}}(1 \rightarrow 0)=\frac{\varepsilon_{1}-\varepsilon_{0, \text { rec }}}{\varepsilon_{1}-\varepsilon_{0}} \cdot 100 \%
\end{aligned}
$$

where $\varepsilon_{1, \text { load }}$ represents the maximum strain under the load, $\varepsilon_{1}$ is the strain after cooling and load removal, and $\varepsilon_{0, \text { rec }}$ is the recovered strain.

\subsection{Self-healing effect}

In the self-healing tests, dumbbell-shaped specimens were cut into two separate parts with a clean blade. Then, the fracture surfaces were placed back together by gently pressing to ensure good contact between the cut faces to heal in a vacuum oven at $90{ }^{\circ} \mathrm{C}$ for $150 \mathrm{~min}$. Finally, the samples were slowly cooled at room temperature for 5 days to complete the crystallization area of PCO. After healing, the samples were stretched to fracture at a cross-head speed of $500 \mathrm{~mm} \cdot \mathrm{min}^{-1}$ at $25^{\circ} \mathrm{C}$ again. Healing efficiency was evaluated by Equation (6)), comparing the tensile strength of the healed samples $\sigma_{b}^{\text {healed }}$ and the virgin samples $\sigma_{\mathrm{b}}^{\text {virgin }}$ as follows:

Healing efficiency $=\frac{\sigma_{\mathrm{b}}^{\text {healed }}}{\sigma_{\mathrm{b}}^{\text {virgin }}} \cdot 100 \%$

\section{Results and discussion}

In this study, a novel shape memory elastomer is designed and crosslinked to form smart polymers with shape memory and self-healing ability. These composites were prepared with both a crosslinked network and crystalline phase. The mechanical, thermal, shape memory, and self-healing properties of this elastomer were investigated in this study and were closely linked to the structure of NR/PCO compounds.

\subsection{Curing properties of composites}

First, we studied the effect of the PCO content on the curing and mechanical properties of composites. The scorch time $\left(T_{10}\right)$ in Table 2 increased gradually with increasing $\mathrm{PCO}$ content, indicating that the increase in $\mathrm{PCO}$ content prolonged the processing safety time and reduced the occurrence of scorch during processing. The optimum cure time $\left(T_{90}\right)$ and the values of $M_{\mathrm{H}}, M_{\mathrm{L}}, M_{\mathrm{H}}-M_{\mathrm{L}}$ increased marginally with the increase of PCO content. The increase in $M_{\mathrm{H}}-M_{\mathrm{L}}$ implied an increase in the crosslinking degree. Therefore, we also measured the crosslinking density of composites using the NMR method, and the measured transverse relaxation time $\left(T_{2}\right)$ of NMR was used as a scale for comparing the crosslinking density. These composites completed the transformation from linear macromolecules to crosslinked three-dimensional network structure in the vulcanization

Table 2. Curing characteristics and crosslinking densities of NR/PCO composites.

\begin{tabular}{|l|c|c|c|c|c|}
\hline \multirow{2}{*}{ Properties } & \multicolumn{4}{c|}{ Composites with different ratio of NR/PCO } \\
\cline { 2 - 6 } & & $\mathbf{A}$ & $\mathbf{B}$ & $\mathbf{C}$ & D \\
\hline$M_{\mathrm{H}}$ & {$[\mathrm{dN} \cdot \mathrm{m}]$} & 16.0 & 16.8 & 17.2 & 17.3 \\
\hline$M_{\mathrm{L}}$ & {$[\mathrm{dN} \cdot \mathrm{m}]$} & 0.24 & 0.26 & 0.29 & 0.31 \\
\hline$M_{\mathrm{H}}-M_{\mathrm{L}}$ & {$[\mathrm{dN} \cdot \mathrm{m}]$} & 15.8 & 16.6 & 16.9 & 17.0 \\
\hline$T_{10}$ & {$[\mathrm{~min}]$} & 3.05 & 4.32 & 4.87 & 5.70 \\
\hline$T_{90}$ & {$[\mathrm{~min}]$} & 34.88 & 35.00 & 36.45 & 36.90 \\
\hline$T_{2}$ & {$[\mathrm{~ms}]$} & 2.47 & 2.44 & 2.32 & 2.21 \\
\hline cross-linking density $\cdot 10^{-4}$ & {$\left[\mathrm{~mol} \cdot \mathrm{cm}^{-3}\right]$} & 1.86 & 1.93 & 2.04 & 2.15 \\
\hline
\end{tabular}


process. The change of molecular microstructure and the movement characteristics of macromolecules in composites could be reflected by its NMR transverse relaxation time $\left(T_{2}\right) . T_{2}$ exhibits the molecular motion of the entire network, including the rapid motion of small molecules, free ends, and molecules, as well as the relatively slow motion of the network chain and the slow motion of the entire network. As the crosslinking density of vulcanizates increased, the movement of macromolecules is severely restricted. Therefore, transverse relaxation time $T_{2}$ decreased with the increase of crosslinking density. The trend of $T_{2}$ was also consistent with the equilibrium swelling test method results. The reason for this phenomenon was that the crosslinking network structure decreased with increasing polymer content when the amount of crosslinking agent DCP was fixed.

\subsection{Mechanical properties and cross sections of composites}

Then, the mechanical properties of the composites were investigated and are shown in Table 3 and Figure 1 . The tensile strength marginally decreased from 13.35 to $11.98 \mathrm{MPa}$. However, the elongation at failure, $100 \%$ modulus, and hardness were improved by increasing the PCO content. This phenomenon may be attributed to the fact that PCO is a type of crystallizable polymer with certain plasticity. Therefore,

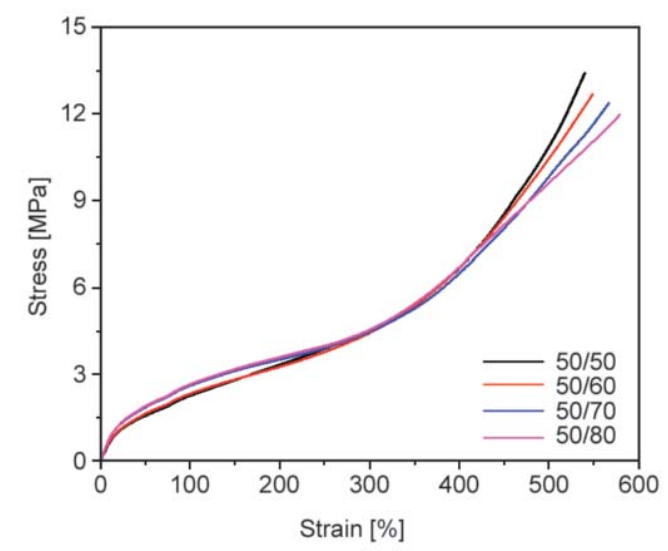

Figure 1. Stress-strain curves of the NR/PCO blends with different ratio of NR/PCO. increasing the PCO dosage increased the hardness, $100 \%$ modulus and elongation at failure of the composites. The decrease of tensile strength may be due to the increase of PCO content. The strength of PCO material itself is very low.

The morphological structure of the NR/PCO composites was observed from the SEM images in Figure 1. We found that the microscopic morphology of composites presented an obvious continuous phase structure from Figures 2a to $2 d$. The relatively smooth surface indicated good compatibility between the $\mathrm{NR}$ and PCO in the composites. This difference in microscopic morphology inevitably affected the performance of composites.

\subsection{DSC analysis}

In semicrystalline SMPs, the melting and reappearance of the crystalline domain determine the fixation of the temporary shape and the restoration of the original shape of composites. Therefore, it is essential to identify the melting point of samples to determine the transition temperature. The melting temperature of the composites could be obtained from the DSC curves (Figure 3). We found that the melting peak locations of PCO portions significantly shifted to the high-temperature direction with the increase of PCO content. The melting peak area also increased due to the increase in PCO content. The degree of crystallinity could be calculated according to Equation (3). We found that the crystallinity of PCO increased from 24.41 to $26.06 \%$, as shown in Table 4 . Therefore, we showed that the increase in crystallinity in composites might have a strong influence on the material properties.

\subsection{Shape memory effect analysis}

DMA was adapted to investigate and characterize the shape memory properties of NR/PCO composites. In shape memory behaviors, the crosslinked network generated in both the NR and PCO portions acted as a fixed phase, while the crystalline regions of the PCO portions acted as a reversible phase. In the

Table 3. Mechanical properties of NR/PCO composites.

\begin{tabular}{|lc|c|c|c|c|}
\hline \multirow{2}{*}{} & \multirow{2}{*}{ Properties } & \multicolumn{4}{c|}{ Composites with different ratio of NR/PCO } \\
\cline { 3 - 6 } & & $\mathbf{A}$ & $\mathbf{B}$ & $\mathbf{C}$ & D \\
\hline Tensile strength & {$[\mathrm{MPa}]$} & 13.35 & 12.69 & 12.37 & 11.98 \\
\hline $100 \%$ modulus & {$[\mathrm{MPa}]$} & 2.25 & 2.50 & 2.58 & 2.67 \\
\hline Elongation at break & {$[\%]$} & 537 & 549 & 565 & 579 \\
\hline Hardness & {$[$ Shore A] } & 63 & 69 & 74 & 77 \\
\hline
\end{tabular}




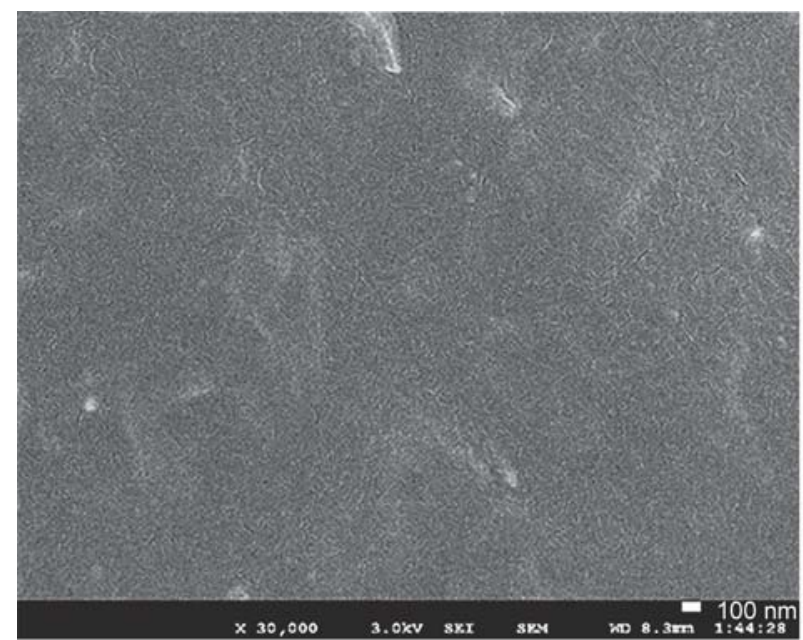

a)

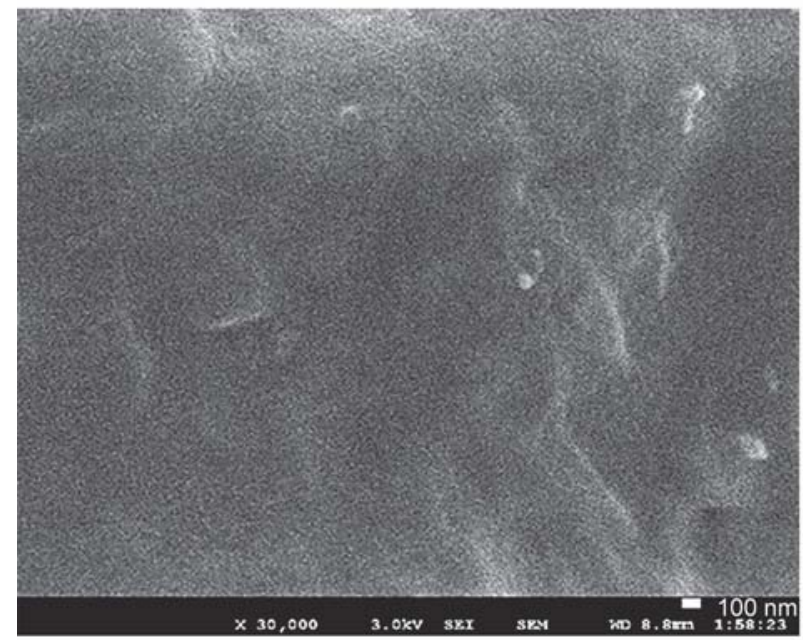

c)

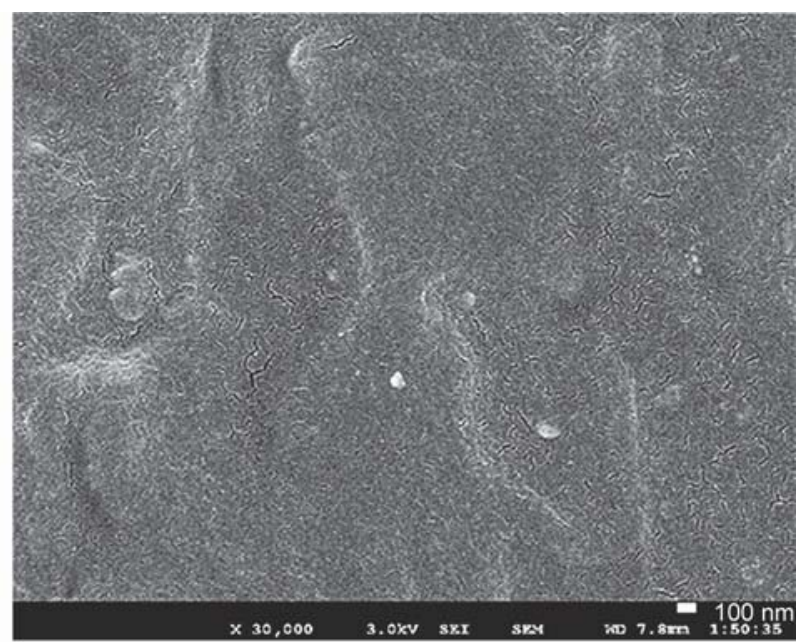

b)

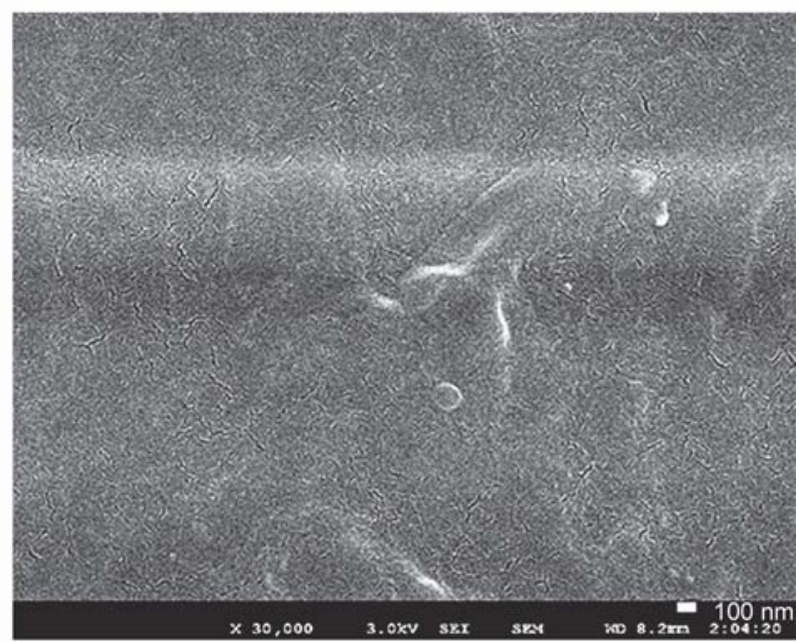

d)

Figure 2. SEM images of the NR/PCO blends with different ratio of NR/PCO: (a) 50/50; (b) 50/60; (c) 50/70; (d) 50/80.
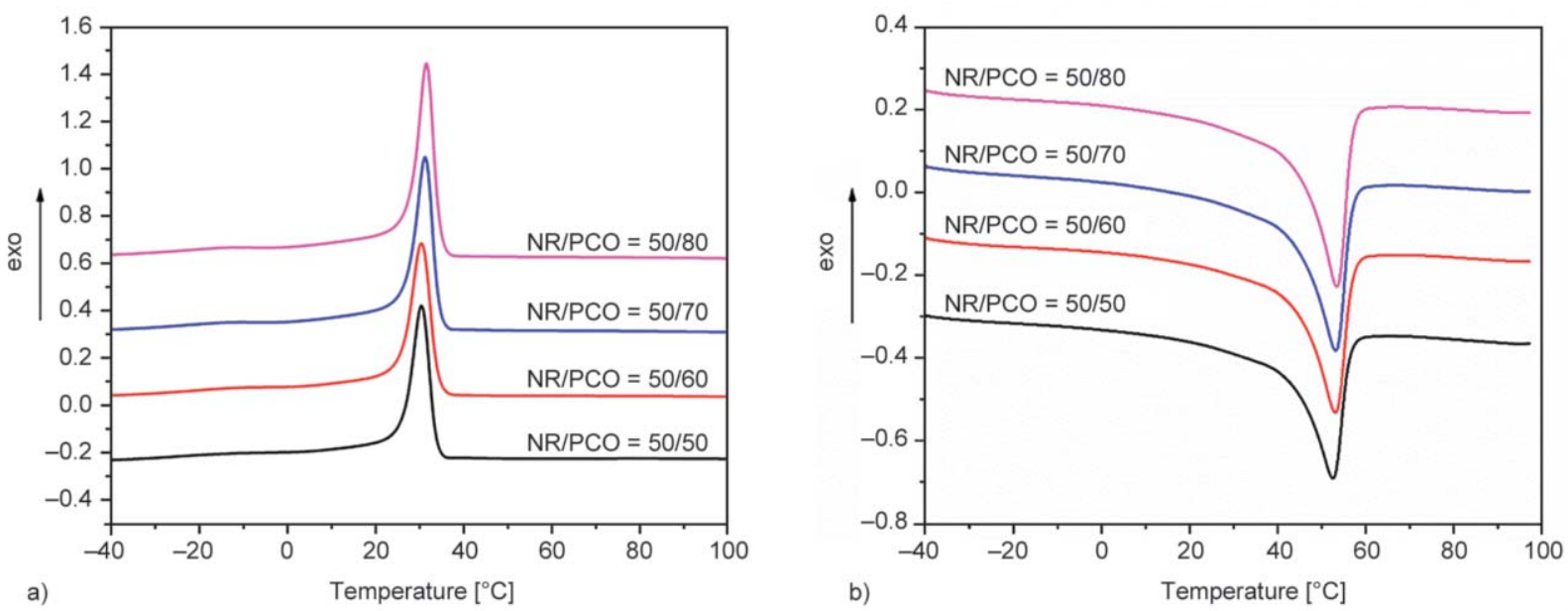

Figure 3. Differential Scanning Calorimeter (DSC) curves of the NR/PCO blends with different ratio of NR/PCO: (a) cooling curves and (b) heating curves.

DMA test, composites were stretched at high temperature, given a temporary shape, fixed to a temporary shape at low temperature, and heated again to complete the shape recovery process. The shape fixing rate and shape recovery rate could be calculated from the obtained DMA curves. Using Equations (4) and (5), the shape fixation and recovery rate of the composites remained at approximately $94 \%$ in the DMA test (Figure 4 and Table 5). The shape fixation and recovery rate of the composites also increased 

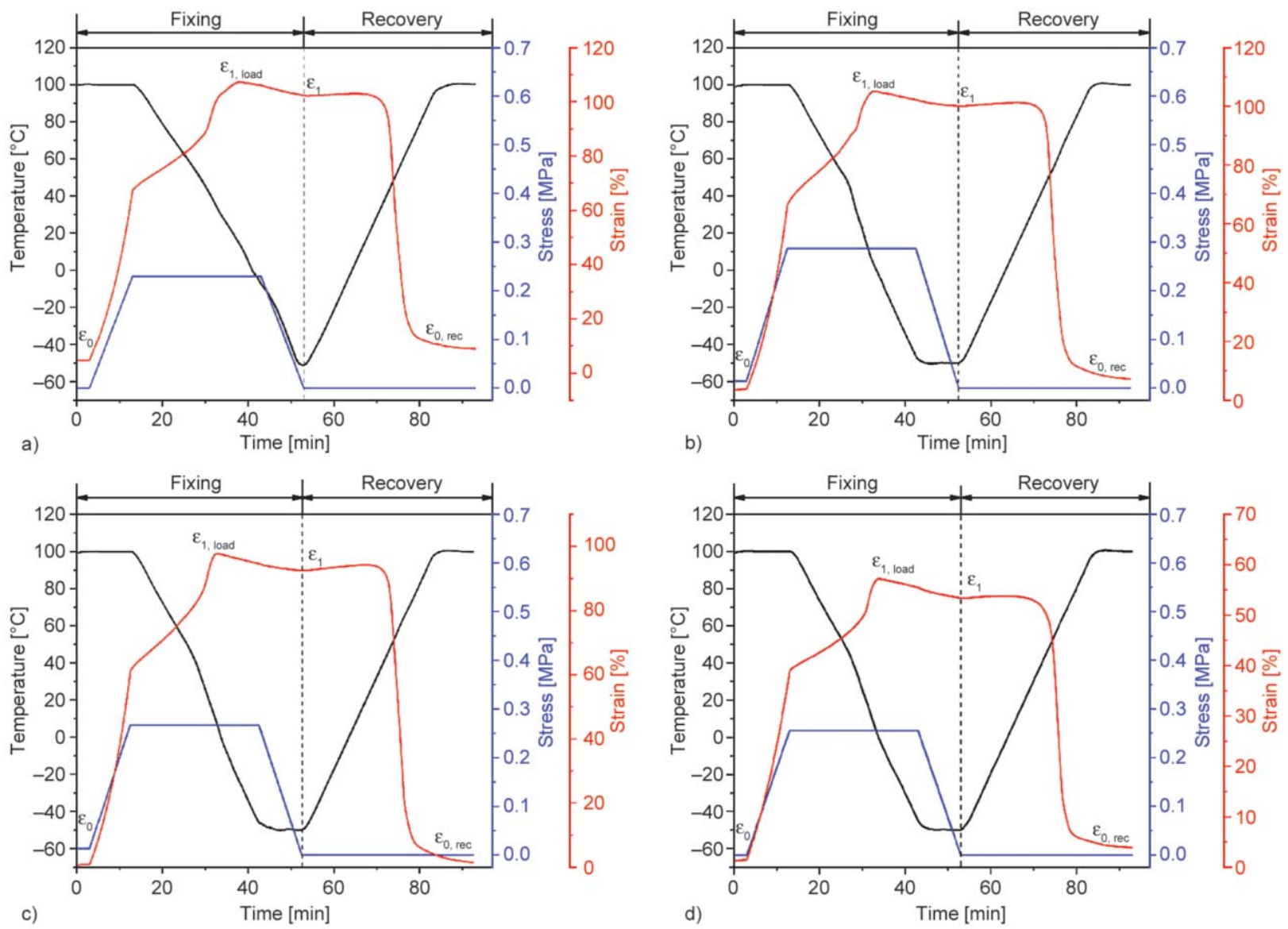

Figure 4. Shape memory properties of the NR/PCO blends with different ratio of NR/PCO: (a) 50/50; (b) 50/60; (c) 50/70; (d) $50 / 80$.

Table 4. Crystalline properties of NR/ PCO composites.

\begin{tabular}{|cc|c|c|c|c|}
\hline \multirow{2}{*}{ Properties } & \multicolumn{4}{|c|}{ Composites with different ratio of NR/PCO } \\
\cline { 3 - 6 } & & $\mathbf{A}$ & $\mathbf{B}$ & $\mathbf{C}$ & $\mathbf{D}$ \\
\hline$X_{\mathrm{c}(\mathrm{PCO})}$ & {$[\%]$} & 24.41 & 24.55 & 25.61 & 26.06 \\
\hline$T_{\mathrm{m}(\mathrm{PCO})}$ & {$\left[{ }^{\circ} \mathrm{C}\right]$} & 52.51 & 53.06 & 53.09 & 53.38 \\
\hline
\end{tabular}

marginally with increasing PCO content. Results were closely related to the increase in crystallinity and crosslinking degree of the composites. In shape memory behavior, the crystallization zone determined the fixed rate of shape memory performance, and the crosslinking structures of NR and PCO played a decisive role in the recovery rate of shape memory performance. Therefore, the improvement of crystallinity and crosslinking density in the composite improved the shape memory properties of the composite.

\subsection{Self-healing analysis}

In the self-healing experiment, we first cut the composites in half and then healed them via thermal assistance. Intuitive comparison photos before and after healing are shown in Figure 5. As shown in Figure 5, the samples maintained the original dimensions.

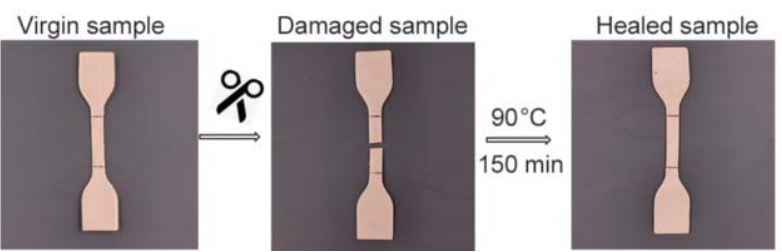

Figure 5. Representative photographs showing the healing process of NR/PCO blends.

There were no marked visual cracks after healed at $90^{\circ} \mathrm{C}$ for 150 minutes. To test the properties of the composites after healing, we also performed mechanical tests on these healed samples. The healing efficiency was quantified by comparing the tensile strengths of the healed samples and the virgin samples via Equation (6). We found that the tensile strength of the healed composites increased gradually with increasing PCO content, as shown in Figure 6. All healed samples fractured at a much lower tensile strength than the corresponding original samples. The highest healing efficiency of the composites reached $19.03 \%$. Such behavior could be explained by the physical diffusion of molecular chains in the repaired composites. When the temperature 


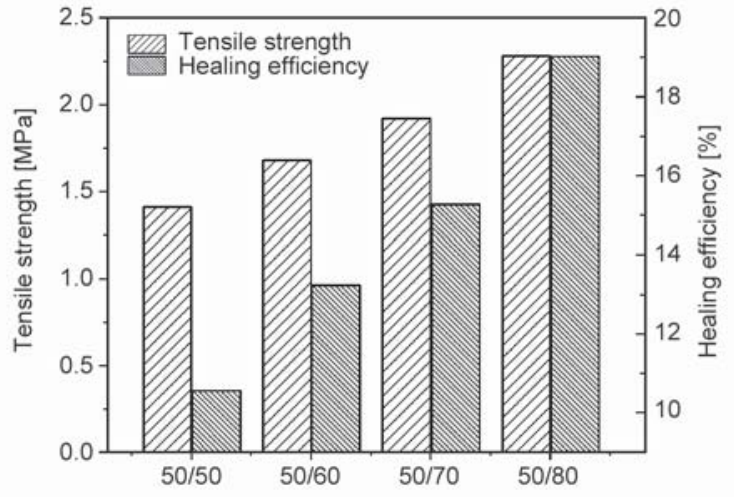

Figure 6. Tensile strength and healing efficiency of NR/PCO composites after healing.

was higher than the melting point of $\mathrm{PCO}$, the uncross-linked PCO component might experience physical diffusion and melt bonding, which were the primary methods of self-healing in composites.

Therefore, schematic diagrams were proposed to clearly show the shape memory and self-healing behavior of NR/PCO composites. In Figure 7, the NR and $\mathrm{PCO}$ portions are drawn in red and blue, respectively. The disorder curves represent amorphous chain segments in the composites, and the rectangles represent crystalline regions of the PCO part. The black dots represent crosslinking points in the composites. First, when the sample temperature was kept at $100^{\circ} \mathrm{C}$, all crystalline regions in the composites melted. A temporary shape could be formed and fixed under external loading and cooling processes. After the load is removed, the specimens could return to their original shapes by reheating. Therefore, the composites could be softened via heat, formed, and fixed a temporary shape through a cooling process. This process is how the shape memory process of composites is completed.

Schematic diagrams of the self-healing behavior are shown in Figure 8. When two fractured samples are

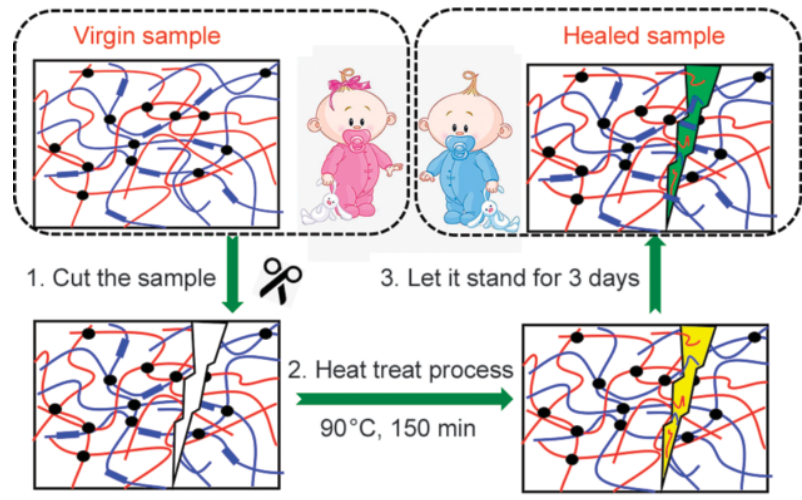

Figure 8. Scheme diagrams for NR/PCO blends: self-healing behaviours.

placed together, the mobility of the molecular chains is enhanced when the temperature rises above the melting temperature of the PCO component. The improvement of the mobility of molecular chains increases the entanglement of molecular chains through mutual diffusion. Therefore, the physical crosslinking of the molecular chains would form under the driving of thermodynamics. Then, these composites undergo fusion bonding, cooling, and crystallization at room temperature to obtain certain strength. However, the migration of molecular chains is limited by the chemical crosslinking network, resulting in little molecular entanglement at the interface, low recovery of mechanical properties, and an inability to achieve uniformity in composites.

Therefore, these two schematic diagrams could explain the observed relationship between the internal microstructures and the macroscopic properties of

Table 5. $R_{\mathrm{f}}$ and $R_{\mathrm{r}}$ values of NR/PCO composites.

\begin{tabular}{|cc|c|c|c|c|}
\hline \multirow{2}{*}{ Properties } & \multicolumn{4}{|c|}{ Composites with different ratio of NR/PCO } \\
\cline { 3 - 6 } & & $\mathbf{A}$ & $\mathbf{B}$ & $\mathbf{C}$ & $\mathbf{D}$ \\
\hline$R_{\mathrm{f}}$ & {$[\%]$} & 92.79 & 94.74 & 94.96 & 95.13 \\
\hline$R_{\mathrm{r}}$ & {$[\%]$} & 94.45 & 95.41 & 95.89 & 98.92 \\
\hline
\end{tabular}

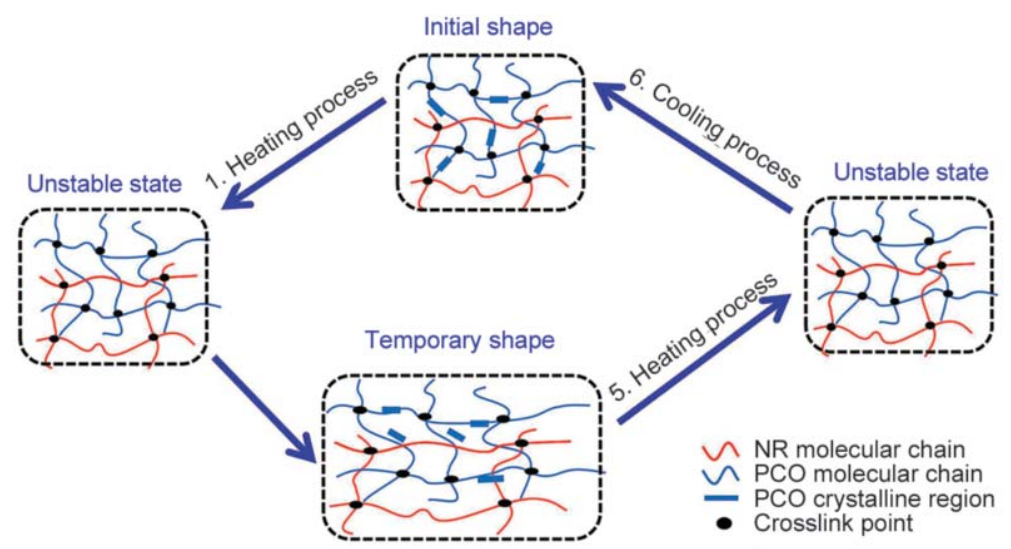

Figure 7. Scheme diagrams for NR/PCO blends: shape memory effect. 
the materials and describe the thermally activated shape memory and thermally assisted self-healing effect of NR/PCO composites.

\section{Conclusions}

In this study, shape-memory NR/PCO composites with thermally assisted self-healing capability were prepared via a simple mechanical blending method. Then, the effects of the PCO content on the microstructure, mechanical, vulcanization and thermal, shape memory and self-healing properties were explored. We found that the produced composites had excellent shape memory properties $\left(R_{\mathrm{f}}=95.13 \%\right.$, $\left.R_{\mathrm{r}}=98.92 \%\right)$ when NR/PCO blending ratio was $50 / 80$. The composites exhibited a certain extent of self-healing properties at an elevated temperature $\left(90^{\circ} \mathrm{C}\right)$, which was attributed to molecular chain interdiffusion processes. The shape memory and thermally assisted self-healing properties could be improved by increasing the $\mathrm{PCO}$ content. The NR/PCO showed excellent mechanical, shape memory, and self-healing properties $\left(R_{\mathrm{f}}=94.57 \%, R_{\mathrm{r}}=98.92 \%\right.$, and healing efficiency $=19.03 \%$ ) when the blending ratio was $50 / 80$.

\section{Acknowledgements}

Financial support from the National Natural Science Foundation of China (Grant No. 51303092, 51573194), Major scientific and technological innovation projects in Shandong Province, China [2019JZZY020223], and the Natural Science Foundation of Shandong province, China [ZR2019MEM016, ZR2019MEM028] is gratefully acknowledged.

\section{References}

[1] Behl M., Razzaq M. Y., Lendlein A.: Multifunctional shape-memory polymers. Advanced Materials, 22, 3388-3410 (2010). https://doi.org/10.1002/adma.200904447

[2] Xie T.: Recent advances in polymer shape memory. Polymer, 52, 4985-5000 (2011). https://doi.org/10.1016/j.polymer.2011.08.003

[3] Lai S-M., Lan Y-C.: Shape memory properties of meltblended polylactic acid (PLA)/thermoplastic polyurethane (TPU) bio-based blends. Journal of Polymer Research, 20, 140/1-140/8 (2013). https://doi.org/10.1007/s10965-013-0140-6

[4] Gong X., Tan K., Deng Q., Shen S.: Athermal shape memory effect in magnetoactive elastomers. ACS Applied Materials and Interfaces, 12, 16930-16936 (2020). https://doi.org/10.1021/acsami.0c01453
[5] Hombunma P., Parnklang T., Mora P., Jubsilp C., Rimdusit S.: Shape memory polymers from bio-based benzoxazine/epoxidized natural oil copolymers. Smart Materials and Structures, 29, 015036/1-015036/13 (2020). https://doi.org/10.1088/1361-665X/ab49e5

[6] Guo W., Lu C-H., Orbach R., Wang F., Qi X-J., Cecconello A., Seliktar D., Willlner I.: pH-stimulated DNA hydrogels exhibiting shape-memory properties. Advanced Materials, 27, 73-78 (2015). https://doi.org/10.1002/adma.201403702

[7] Hu Y., Lu C-H., Guo W., Aleman-Garcia M. A., Ren J., Willner I.: A shape memory acrylamide/DNA hydrogel exhibiting switchable dual pH-responsiveness. Advanced Functional Materials, 25, 6867-6874 (2016). https://doi.org/10.1002/adfm.201503134

[8] Lendlein A., Jiang H., Jünger O., Langer R.: Light-induced shape-memory polymers. Nature, 434, 879-882 (2005). https://doi.org/10.1038/nature03496

[9] Lu H., Yao Y., Huang W. M., Leng J., Hui D.: Significantly improving infrared light-induced shape recovery behavior of shape memory polymeric nanocomposite via a synergistic effect of carbon nanotube and boron nitride. Composites Part B: Engineering, 62, 256-261 (2014).

https://doi.org/10.1016/j.compositesb.2014.03.007

[10] Mendez J., Annamalai P. K., Eichhorn S. J., Rusli R., Rowan S. J., Foster E. J., Weder C.: Bioinspired mechanically adaptive polymer nanocomposites with water-activated shape-memory effect. Macromolecules, 44, 6827-6835 (2011). https://doi.org/10.1021/ma201502k

[11] Zhang Z-X., Qi X-D., Li S-T., Yang J-H., Zhang N., Huang T., Wang Y.: Water-actuated shape-memory and mechanically-adaptive poly(ethylene vinyl acetate) achieved by adding hydrophilic poly(vinyl alcohol). European Polymer Journal, 98, 237-245 (2018). https://doi.org/10.1016/j.eurpolymj.2017.11.031

[12] Cuevas J. M., Alonso J., German L., Iturrondobeitia M., Laza J. M., Vilas J. L., León L. M.: Magneto-active shape memory composites by incorporating ferromagnetic microparticles in a thermo-responsive polyalkenamer. Smart Materials and Structures, 18, 075003/1075003/10 (2009). https://doi.org/10.1088/0964-1726/18/7/075003

[13] Yang D., Huang W., He X., Xie M.: Electromagnetic activation of a shape memory copolymer matrix incorporating ferromagnetic nanoparticles. Polymer International, 61, 38-42 (2012). https://doi.org/10.1002/pi.3188

[14] Yu K., Westbrook K. K., Kao P. H., Leng J., Qi H. J.: Design considerations for shape memory polymer composites with magnetic particles. Journal of Composite Materials, 47, 51-63 (2013). https://doi.org/10.1177/0021998312447647 
[15] Gong X., Liu L., Liu Y., Leng J.: An electrical-heating and self-sensing shape memory polymer composite incorporated with carbon fiber felt. Smart Materials and Structures, 25, 035036/1-035036/10 (2016). https://doi.org/10.1088/0964-1726/25/3/035036

[16] Gök M. O., Bilir M. Z., Gürcüm B. H.: Shape-memory applications in textile design. Procedia Social and Behavioral Sciences, 195, 2160-2169 (2015). https://doi.org/10.1016/j.sbspro.2015.06.283

[17] Eisenhaure J. D., Rhee S. I., Al-Okaily A. M., Carlson A., Ferreira P. M., Kim S.: The use of shape memory polymers for microassembly by transfer printing. Journal of Microelectromechanical Systems, 23, 1012-1014 (2014).

https://doi.org/10.1109/JMEMS.2014.2345274

[18] Leng J., Yu K., Sun J., Liu Y.: Deployable morphing structure based on shape memory polymer. Aircraft Engineering and Aerospace Technology, 87, 218-223 (2015).

https://doi.org/10.1108/AEAT-06-2013-0118

[19] Lendlein A., Langer R.: Biodegradable, elastic shapememory polymers for potential biomedical applications. Science, 296, 1673-1676 (2002). https://doi.org/10.1126/science.1066102

[20] Delaey J., Dubruel P., van Vlierberghe S.: Shape-memory polymers for biomedical applications. Advanced Functional Materials, 30, 1909047/1-1909047/23 (2020). https://doi.org/10.1002/adfm.201909047

[21] Leng J., Lan X., Liu Y., Du S.: Shape-memory polymers and their composites: Stimulus methods and applications. Progress in Materials Science, 56, 1077 1135 (2011). https://doi.org/10.1016/j.pmatsci.2011.03.001

[22] Cuevas J. M., Laza J. M., Rubio R., German L., Vilas J. L., León L. M.: Development and characterization of semi-crystalline polyalkenamer based shape memory polymers. Smart Materials and Structures, 20, 035003/1035003/9 (2011). https://doi.org/10.1088/0964-1726/20/3/035003

[23] Basit A., L'Hostis G., Durand B.: Multi-shape memory effect in shape memory polymer composites. Materials Letters, 74, 220-222 (2012). https://doi.org/10.1016/j.matlet.2012.01.113

[24] Sun L., Huang W. M.: Mechanisms of the multi-shape memory effect and temperature memory effect in shape memorypolymers. Soft Matter, 6, 4403-4406 (2010). https://doi.org/10.1039/c0sm00236d

[25] Lu L., Li G.: One-way multishape-memory effect and tunable two-way shape memory effect of ionomer poly (ethylene-co-methacrylic acid). ACS Applied Materials and Interfaces, 8, 14812-14823 (2016).

https://doi.org/10.1021/acsami.6b04105

[26] Wool R. P.: Self-healing materials: A review. Soft Matter, 4, 400-418 (2008).

https://doi.org/10.1039/B711716G

[27] Urban M. W.: The chemistry of self-healing. Nature Chemistry, 4, 80-82 (2012).

https://doi.org/10.1038/nchem.1249
[28] Zhang R., Yan T., Lechner B-D., Schröter K., Liang Y., Li B., Furtado F., Sun P., Saalwächter K.: Heterogeneity, segmental and hydrogen bond dynamics, and aging of supramolecular self-healing rubber. Macromolecules, 46, 1841-1850 (2013). https://doi.org/10.1021/ma400019m

[29] Liu Y., Li Z., Liu R., Liang Z., Yang J., Zhang R., Zhou Z., Nie Y.: Design of self-healing rubber by introducing ionic interaction to construct a network composed of ionic and covalent cross-linking. Industrial and Engineering Chemistry Research, 58, 14848-14858 (2019). https://doi.org/10.1021/acs.iecr.9b02972

[30] Rehman H. U., Chen Y., Hedenqvist M. S., Li H., Xue W., Guo Y., Guo Y., Duan H., Liu H.: Self-healing shape memory PUPCL copolymer with high cycle life. Advanced Functional Materials, 28, 1704109/1-1704109/13 (2018).

https://doi.org/10.1002/adfm.201704109

[31] Nji J., Li G.: Damage healing ability of a shape-memory-polymer-based particulate composite with small thermoplastic contents. Smart Materials and Structures, 21, 025011/1-025011/10 (2012). https://doi.org/10.1088/0964-1726/21/2/025011

[32] Yao Y., Wang J., Lu H., Xu B., Fu Y., Liu Y., Leng J.: Thermosetting epoxy resin/thermoplastic system with combined shape memory and self-healing properties. Smart Materials and Structures, 25, 015021/1-015021/8 (2016). https://doi.org/10.1088/0964-1726/25/1/015021

[33] Luo X., Mather P. T.: Shape memory assisted self-healing coating. ACS Macro Letters, 2, 152-156 (2013). https://doi.org/10.1021/mz400017x

[34] Li G., Nettles D.: Thermomechanical characterization of a shape memory polymer based self-repairing syntactic foam. Polymer, 51, 755-762 (2010). https://doi.org/10.1016/j.polymer.2009.12.002

[35] Li G., Uppu N.: Shape memory polymer based selfhealing syntactic foam: 3-D confined thermomechanical characterization. Composites Science and Technology, 70, 1419-1427 (2010).

https://doi.org/10.1016/j.compscitech.2010.04.026

[36] Nji J., Li G.: A self-healing 3D woven fabric reinforced shape memory polymer composite for impact mitigation. Smart Materials and Structures, 19, 035007/1035007/9 (2010). https://doi.org/10.1088/0964-1726/19/3/035007

[37] Raidt T., Hoeher R., Meuris M., Katzenberg F., Tiller J. C.: Ionically cross-linked shape memory polypropylene. Macromolecules, 49, 6918-6927 (2016). https://doi.org/10.1021/acs.macromol.6b01387

[38] Katzenberg F., Heuwers B., Tiller J. C.: Superheated rubber for cold storage. Advanced Materials, 23, 19091911 (2011). https://doi.org/10.1002/adma.201100408

[39] Katzenberg F., Tiller J. C.: Shape memory natural rubber. Journal of Polymer Science Part B: Polymer Physics, 54, 1381-1388 (2016). https://doi.org/10.1002/polb.24040 
[40] Quitmann D., Gushterov N., Sadowski G., Katzenberg F., Tiller J. C.: Environmental memory of polymer networks under stress. Advanced Materials, 26, 34413444 (2014).

https://doi.org/10.1002/adma.201305698

[41] Heuwers B., Quitmann D., Katzenberg F., Tiller J. C.: Stress-induced melting of crystals in natural rubber: A new way to tailor the transition temperature of shape memory polymer. Macromolecular Rapid Communications, 33, 1517-1522 (2012).

https://doi.org/10.1002/marc.201200313

[42] Heuwers B., Quitmann D., Hoeher R., Reinders F. M., Tiemeyer S., Sternemann C., Tolan M., Katzenberg F., Tiller J. C.: Stress-induced stabilization of crystals in shape memory natural rubber. Macromolecular Rapid Communications, 34, 180-184 (2013).

https://doi.org/10.1002/marc.201200594

[43] Hernández M., Grande A. M., Dierkes W., Bijleveld J. C., van der Zwaag S., García S. J.: Turning vulcanized natural rubber into a self-healing polymer: Effect of the disulfide/polysulfide ratio. ACS Sustainable Chemistry and Engineering, 5, 11127-11129 (2017).

https://doi.org/10.1021/acssuschemeng.6b01760

[44] Xu C., Cao L., Lin B., Liang X., Chen Y.: Design of self-healing supramolecular rubbers by introducing ionic cross-links into natural rubber via a controlled vulcanization. ACS Applied Materials and Interfaces, 8, 17728-11737 (2016). https://doi.org/10.1021/acsami.6b05941

[45] Liu C., Chun S. B., Mather P. T., Zheng L., Haley E. H., Coughlin E. B.: Chemically cross-linked polycyclooctene: Synthesis, characterization, and shape memory behavior. Macromolecules, 35, 9868-9874 (2002). https://doi.org/10.1021/ma021141j
[46] Radusch H-J., Kolesov I., Gohs U., Heinrich G.: Multiple shape-memory behavior of polyethylene/polycyclooctene blends cross-linked by electron irradiation. Macromolecular Materials and Engineering, 297, 12251234 (2012). https://doi.org/10.1002/mame.201200204

[47] Wang Z., Zhao J., Chen M., Yang M., Tang L., Dang Z-M., Chen F., Huang M., Dong X.: Dually actuated triple shape memory polymers of cross-linked polycyclooctene-carbon nanotube/polyethylene nanocomposites. ACS Applied Materials and Interfaces, 6, 2005120059 (2014).

https://doi.org/10.1021/am5056307

[48] Hong S. B., Hong S. J., Kang T. H., Youk J. H., Yu W. R.: Optical and shape memory properties of semicrystalline poly(cyclooctene) upon cold-drawing. Journal of Polymer Science Part B: Polymer Physics, 55, 15951607 (2017). https://doi.org/10.1002/polb.24415

[49] Segiet D., Neuendorf L. M., Tiller J. C., Katzenberg F.: Realizing a shape-memory effect for synthetic rubber (IR). Polymer, 203, 122788/1-122788/13 (2020). https://doi.org/10.1016/j.polymer.2020.122788

[50] Parker A. A., Marcinco J. J., Rinaldi P., Hedrick D. P., Ritchey W. M.: A relationship between NMR cross-polarization rates and dynamic storage modulae of polymers. Journal of Applied Polymer Science, 48, 677-684 (1993). https://doi.org/10.1002/app.1993.070480410

[51] Schneider W. A., Müller M. F.: Crystallinity of transpolyoctenamer: Characterization and influence of sample history. Journal of Molecular Catalysis, 46, 395403 (1988). https://doi.org/10.1016/0304-5102(88)85111-3 